Acta Crystallographica Section E

Structure Reports

Online

ISSN 1600-5368

H. S. Yathirajan, ${ }^{a}$ S. Bindya, ${ }^{b}$ B. Narayana, ${ }^{\text {C }}$ B. K. Sarojini ${ }^{\mathrm{d}}$ and Michael Bolte ${ }^{\mathbf{e}_{*}}$

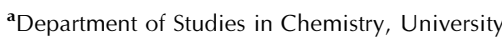
of Mysore, Manasagangotri, Mysore 570 006, India, ${ }^{\mathbf{b}}$ Department of Studies in Chemistry,

University of Mysore, Manasagangotri, Mysore 570 006, India, ' Department of Chemistry, Mangalore University, Mangalagangotri 574 199, India, dDepartment of Chemistry, P.A. College of Engineering, Nadupadavu, Mangalore 574 153, India, and ${ }^{\mathbf{e}}$ Institut für Anorganische Chemie, J. W. Goethe-Universität Frankfurt, Max-von-Laue-Strasse 7, 60438

Frankfurt/Main, Germany

Correspondence e-mail:

bolte@chemie.uni-frankfurt.de

\section{Key indicators}

Single-crystal X-ray study

$T=173 \mathrm{~K}$

Mean $\sigma(\mathrm{C}-\mathrm{C})=0.002 \AA$

$R$ factor $=0.031$

$w R$ factor $=0.084$

Data-to-parameter ratio $=22.9$

For details of how these key indicators were automatically derived from the article, see http://journals.iucr.org/e.

\title{
4-(Methylsulfanyl)benzaldehyde thiosemicarbazone
}

The title compound, $\mathrm{C}_{9} \mathrm{H}_{11} \mathrm{~N}_{3} \mathrm{~S}_{2}$, crystallizes with two molecules in the asymmetric unit, which differ mainly in the degree of planarity. The $\mathrm{C}=\mathrm{N}$ double bonds are trans configured. Geometric parameters are in the usual ranges. The crystal structure is characterized by $\mathrm{N}-\mathrm{H} \cdots \mathrm{N}$ and $\mathrm{N}-$ $\mathrm{H}$...S hydrogen bonds.

\section{Comment}

Thiosemicarbazones (TSCs) of aromatic aldehydes and ketones are widely known as carcinostatic and antimicrobial agents. It has been found that silyl-substituted furfural TSCs possess neurotropic activity (Lukevles et al., 1993). TSCs of arylidene and aryl aldehydes and ketones have shown anticonvulsant activity in maximal electroshock seizure tests (Dimmock et al., 1986, 1990, 1991). In view of the importance of thiosemicarbazones, a new thiosemicarbazone, (I), has been prepared and its crystal structure is reported here.<smiles>CSc1ccc(/C=N/NC(N)=S)cc1</smiles>

(I)

A perspective view of (I) is shown in Fig. 1. Bond lengths and angles can be regarded as normal (Cambridge Structural Database, Version 5.27, November 2005 updated August 2006; MOGUL Version 1.1; Allen, 2002). The $\mathrm{C}=\mathrm{N}$ double bonds are trans configured. Whereas one molecule (labelled with suffix $A$ ) is essentially planar (r.m.s. deviation $=0.062 \AA$ for all non-H atoms) the other one deviates markedly from planarity (r.m.s. deviation $=0.262 \AA$ for all non- $\mathrm{H}$ atoms). The methylsulfanyl residues are coplanar with the benzene rings (Table 1). The thiosemicarbazone units are planar (r.m.s. deviation $=0.036 \AA$ for the non-planar molecule and $0.014 \AA$ for molecule $A$ ), but they form different dihedral angles with the benzene ring, viz. $25.19(4)^{\circ}$ for the non-planar molecule and $7.32(6)^{\circ}$ for molecule $A$. Both molecules show an intramolecular $\mathrm{N}-\mathrm{H} \cdots \mathrm{N}$ contact and two $\mathrm{N}-\mathrm{H} \cdots \mathrm{S}$ hydrogen bonds (Table 2). It is remarkable that only the thiocarbonyl S atom acts as an acceptor for hydrogen bonds, while the methylsulfanyl $\mathrm{S}$ atom is not involved in hydrogen bonds.

\section{Experimental}

A mixture of 4-methylsulfanylbenzaldehyde $(1.52 \mathrm{~g}, 0.01 \mathrm{~mol})$ and thiosemicarbazide $(0.91 \mathrm{~g}, 0.01 \mathrm{~mol})$ in ethanol $(15 \mathrm{ml})$ was refluxed
Received 24 November 2006 Accepted 24 November 2006 


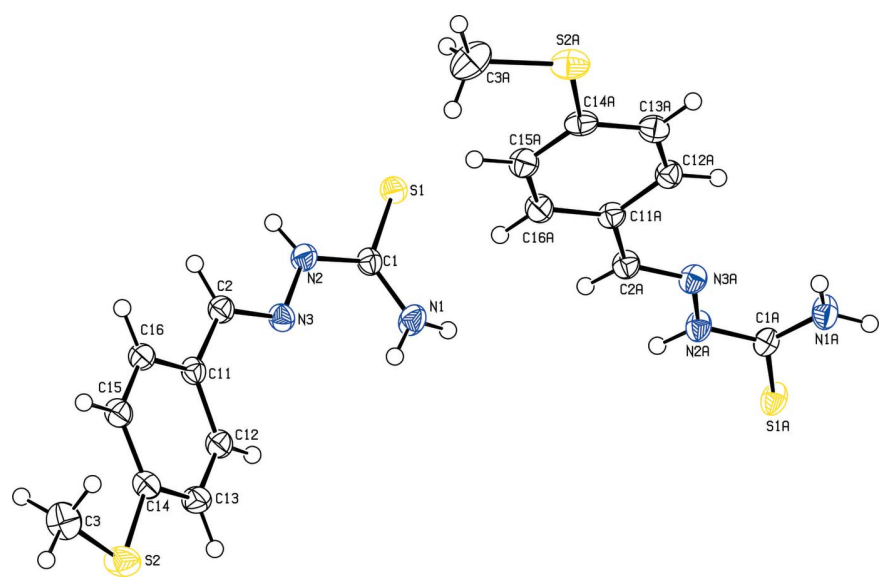

Figure 1

Perspective view of the two molecules in the asymmetric unit of the title compound with the atom numbering; displacement ellipsoids are drawn at the $50 \%$ probability level.

for $3 \mathrm{~h}$ on a water bath. The precipitated solid was filtered, washed with water, dried and recrystallized from acetone (yield: $81 \%$; m.p. 463-465 K). Analysis (\%) found (calculated) for $\mathrm{C}_{9} \mathrm{H}_{11} \mathrm{~N}_{3} \mathrm{~S}_{2}$ : C 47.84 (47.97), H 4.85 (4.92), N 18.54 (18.65), S 28.38 (28.46).

\section{Crystal data}

$\mathrm{C}_{9} \mathrm{H}_{11} \mathrm{~N}_{3} \mathrm{~S}_{2}$
$M_{r}=225.33$
Triclinic, $P \overline{1}$
$a=8.2052(4) \AA$
$b=9.1947(5) \AA$
$c=15.5994(8) \AA$
$\alpha=106.558(5)^{\circ}$
$\beta=97.573(3)^{\circ}$
$\gamma=100.110(4)^{\circ}$

$$
\begin{aligned}
& V=1089.76(10) \AA^{3} \\
& Z=4 \\
& D_{x}=1.373 \mathrm{Mg} \mathrm{m}^{-3} \\
& \text { Mo } K \alpha \text { radiation } \\
& \mu=0.45 \mathrm{~mm}^{-1} \\
& T=173 \text { (2) K } \\
& \text { Block, light orange } \\
& 0.38 \times 0.36 \times 0.33 \mathrm{~mm}
\end{aligned}
$$

\section{Data collection}

$\begin{array}{ll}\text { Stoe IPDS-II two-circle } & 36432 \text { measured reflections } \\ \quad \text { diffractometer } & 6421 \text { independent reflections } \\ \omega \text { scans } & 6026 \text { reflections with } I>2 \sigma(I) \\ \text { Absorption correction: multi-scan } & R_{\text {int }}=0.041 \\ \quad(M U L A B S ; \text { Spek, 2003; Blessing, } & \theta_{\max }=30.2^{\circ} \\ 1995) & \\ T_{\min }=0.847, T_{\max }=0.865 & \end{array}$

\section{Refinement}

Refinement on $F^{2}$
$R\left[F^{2}>2 \sigma\left(F^{2}\right)\right]=0.031$
$w R\left(F^{2}\right)=0.084$
$S=1.06$
6421 reflections
280 parameters
H atoms treated by a mixture of
$\quad$ independent and constrained
$\quad$ refinement

Table 1

Selected torsion angles $\left(^{\circ}\right)$.

$\overline{\mathrm{C} 3-\mathrm{S} 2-\mathrm{C} 14-\mathrm{C} 15 \quad 5.08(12) \quad \mathrm{C} 3 A-\mathrm{S} 2 A-\mathrm{C} 14 A-\mathrm{C} 15 A \quad 7.41(12)}$

Table 2

Hydrogen-bond geometry $\left(\AA,^{\circ}\right)$.

\begin{tabular}{lllll}
\hline$D-\mathrm{H} \cdots A$ & $D-\mathrm{H}$ & $\mathrm{H} \cdots A$ & $D \cdots A$ & $D-\mathrm{H} \cdots A$ \\
\hline $\mathrm{N} 1-\mathrm{H} 1 A \cdots \mathrm{S} 1^{\mathrm{i}}$ & $0.873(17)$ & $2.459(17)$ & $3.3254(11)$ & $172.1(15)$ \\
$\mathrm{N} 1-\mathrm{H} 1 B \cdots \mathrm{N} 3$ & $0.875(17)$ & $2.266(16)$ & $2.6364(13)$ & $105.4(12)$ \\
$\mathrm{N} 2-\mathrm{H} 2 \cdots \mathrm{S} 1 A^{\mathrm{i}}$ & $0.854(17)$ & $2.555(18)$ & $3.3412(10)$ & $153.5(15)$ \\
$\mathrm{N} 1 A-\mathrm{H} 1 C \cdots \mathrm{S} 1 A^{\mathrm{i}}$ & $0.869(19)$ & $2.604(19)$ & $3.4707(11)$ & $174.7(17)$ \\
$\mathrm{N} 2 A-\mathrm{H} 2 A \cdots \mathrm{S} 1^{\mathrm{i}}$ & $0.906(17)$ & $2.454(17)$ & $3.3499(10)$ & $169.8(14)$ \\
$\mathrm{N} 1 A-\mathrm{H} 1 D \cdots \mathrm{N} 3 A$ & $0.852(17)$ & $2.302(16)$ & $2.6440(14)$ & $104.2(13)$
\end{tabular}

Symmetry codes: (i) $-x+1,-y,-z+1$; (ii) $-x+1,-y,-z$.

$\mathrm{H}$ atoms were found in a difference map. Those bonded to carbon were refined using a riding model, with $\mathrm{C}-\mathrm{H}=0.95 \AA$ for aromatic and $\mathrm{C}-\mathrm{H}=0.98 \AA$ for methyl groups. $U_{\text {iso }}(\mathrm{H})$ values were set at $1.2 U_{\text {eq }}(\mathrm{C})\left[1.5 U_{\text {eq }}(\right.$ methyl $\left.\mathrm{C})\right]$. In addition, the methyl groups were allowed to rotate but not to tip. $\mathrm{H}$ atoms bonded to $\mathrm{N}$ were freely refined.

Data collection: $X$-AREA (Stoe \& Cie, 2001); cell refinement: $X$ $A R E A$; data reduction: $X$ - $A R E A$; $\operatorname{program}(\mathrm{s})$ used to solve structure: SHELXS97 (Sheldrick, 1997); program(s) used to refine structure: SHELXL97 (Sheldrick, 1997); molecular graphics: PLATON (Spek, 2003); software used to prepare material for publication: SHELXL97 and PLATON.

One of the authors (BKS) thanks AICTE, Government of India, for financial assistance through the Career Award for Young Teacher's Scheme and SB thanks the University of Mysore for research facilities.

\section{References}

Allen, F. H. (2002). Acta Cryst. B58, 380-388.

Blessing, R. H. (1995). Acta Cryst. A51, 33-38.

Dimmock, J. R., Jonnalagadda, S. S. \& Hussein, S. (1990). Eur. J. Med. Chem. 25, 581-588.

Dimmock, J. R., McColl, J. M., Wonko, S. L., Thayer, R. S. \& Hancock, D. S. (1991). Eur. J. Med. Chem. 26, 529-534.

Dimmock, J. R., Smith, D. C. \& Brenner, J. M. (1986). Eur. J. Med. Chem. 21, 187-192.

Lukevlcs, E., Demlcheva, L., Erchak, N. \& Germane, S. (1993). Appl. Organomet. Chem. 7, 543-551.

Sheldrick, G. M. (1997). SHELXS97 and SHELXL97. University of Göttingen, Germany.

Spek, A. L. (2003). J. Appl. Cryst. 36, 7-13.

Stoe \& Cie (2001). $X$-AREA. Stoe \& Cie, Darmstadt, Germany. 